\title{
Canadian Guidelines for the Development of Antidementia Therapies: a Conceptual Summary
}

\author{
Erich Mohr, Howard Feldman and Serge Gauthier
}

\begin{abstract}
The magnitude of the problems faced by Canadian society as a result of an aging population has been identified. Perhaps the most important concern related to this greying of Canada is the increasing incidence of dementia and Alzheimer's disease. Therapeutic options for these disorders have been limited to date. Advances in biotechnology and molecular biology will offer novel approaches to treatment. These and the expansion of more traditional therapeutic avenues require guidelines with the aim of optimizing their development.
\end{abstract}

RÉSUMÉ: Lignes directrices Canadiennes pour le développement de thêrapies antidémence: un sommaire des concepts. L'amplitude des problèmes auxquels fait face la société Canadienne suite au vieillissement de la population a été identifiée. La préoccupation qui est probablement la plus importante à ce sujet est l'incidence croissante de la démence et de la maladie d'Alzheimer. A date, les options thérapeutiques pour traiter ces maladies sont limitées. Les progrès de la biotechnologie et de la biologie moléculaire offriront de nouvelles approches pour leur traitement. Des lignes directrices sont nécessaires dans le but d'optimiser le développement de ces nouvelles approches ainsi que l'expansion des avenues thérapeutiques plus traditionnelles.

Can. J. Neurol. Sci. 1995; 22: 62-71

Dementing disorders are now recognized as being one of the most important challenges facing medicine in the 21 st century. The Canadian Study of Health and Aging (CSHA) ${ }^{1}$ reported that prevalence figures for all types of dementia are 80/1,000 over age 65 and 345/1,000 over age 85 in this country. Current estimates project that by the year 2001 the number of cases of dementia will rise to well over 350,000 in total. Of affected individuals, $65 \%$ have a diagnosis of Alzheimer's disease. 'The direct and indirect cost of care for each patient with Alzheimer's disease has been estimated to vary between US $\$ 26,000$ to as much as $\$ 47,000$ per year (1990 U.S. dollars). ${ }^{2}$ This estimate would translate into a cost of 5 to 9 billion Canadian dollars per year at present. By the turn of the millennium, these figures (in 1990 dollars) may range from 7 to 13 billion Canadian dollars annually. To meet this challenge, both government and the private sector will need to make major investments in terms of broadly based multidisciplinary research.

The limited success of current treatments for dementia and related problems adds urgency to the search for effective therapeutic approaches. Major advances both in molecular biology and biotechnology hold considerable promise in this regard. The rapid growth of research however requires guidelines to allow for an optimized approach to the development of antidementia treatments. The existence of an integrated Canadian network of investigators (Consortium of Canadian Centres for Clinical Cognitive Research, C5R), will allow Canada to play a significant role in addressing this serious problem. The following conceptual guidelines were drafted to provide points of reference to clinical researchers, government and industry in Canada to help meet this important challenge. Medical research is of course rapidly evolving and the following guidelines are likely to require revisions as new knowledge arises.

\section{Diagnosis}

\section{Dementia}

This syndrome consists of cognitive and functional decline and is frequently associated with behavioral sequelae. For the effective evaluation of treatment strategies, a consistent diagnostic framework must be adhered to. While a number of diagnostic criteria have been proposed world-wide, ${ }^{3-5}$ in Canada the DSM-III-R is considered at present to provide the most useful framework for

From the Institute of Mental Health Research, University of Otawa/Royal Ottawa Hospital, Ottawa (E.M.); University of British Columbia, Division of Neurology, Vancouver (H.F.); The McGill Centre for Studies in Aging, McGill University, Montreal (S.G.); Consortium of Canadian Centres for Clinical Cognitive Research, C5R Secretariat at McGill Centre for Stuides in Aging, McGill University, Montreal (E.M., H.F., S.G.).

Portions of this paper are based on the proceedings of a symposium held at the Institute of Mental Health Research in Ottawa on 5 May 1993 and on a presentation given by the authors at a plenary session at the C5R annual meeting in Montreal on 28 October 1993.

RECEIVED MARCH 18, 1994. ACCEPTED IN FINAL FORM JULY 22, 1994.

Reprint requests to: Dr. Erich Mohr, Neuropsychology Lab. Room D733, Ottawa Civic Hospital, 1053 Carling Avenue, Otawa, Ontario, Canada K I Y 4E9 
the definition of dementia in general. This diagnostic standard continues to be revised and will be updated in DSM-IV. Recommendations for the investigative workup of dementia have been outlined in the monograph of the Canadian Consensus Conference of Dementia (Tables 1,2,3). ${ }^{6}$

\section{Alzheimer's disease}

The NINCDS-ADRDA criteria ${ }^{7}$ continue to provide the clinical diagnostic standard. These criteria have been validated both clinically and pathologically. ${ }^{8,9}$ The error rate in diagnosis has been lowered with their rigorous use to $10-15 \%{ }^{89}$ The emergence of biological markers such as apo-lipoprotein E4 ${ }^{10-13}$ will further improve etiologic definition and classification of the Alzheimer syndrome. Other potentially important diagnostic indices in development include B-amyloid-4 fragment markers ${ }^{14-16}$ and the myo-inositol peak on magnetic resonance spectroscopy (MRS). ${ }^{17}$ As a dynamic problem, there will continually be new

Table 1. Conditions suggesting referral for neuroimaging.

History 1) age less than 60 years
2) use of anticoagulants and/or a history of bleeding
disorder
3) recent head trauma
4) previous history of carcinoma (from sites that metasta-
size to brain - for example, lung, breast)
5) unexplained neurological symptoms (e.g., new onset
headaches, seizures)
6) rapid unexplained decline (e.g., over 1 to 2 months) in
cognition and/or functional status
7) "short" duration of dementia (<2 years)
8) history of urinary incontinence and gait disorder early
in the course of dementia as suggestive for NPH (in
the latter stages of Alzheimer's disease, urinary incon-
tinence and gait ataxia commonly occur)

Physical 1) localizing signs (e.g., hemiparesis, Babinski response)

2) gait ataxia

Reprinted from "Organizing Committee, Canadian consensus conference on the assessment of dementia..." with the Permission of the Canadian Medical Association.

Table 2. Conditions that may confound the diagnosis of dementia.

1) sensory disorders (e.g., blindness and/or deafness)

2) psychotic symptoms (pre-existing as opposed to late in the course of dementia)

3) aphasia/dysarthria

4) language incompatibility between patient and physician

5) mental retardation

6) combination of any of the above, especially in a patient of a low educational level

Reprinted from "Organizing Committee, Canadian consensus conference on the assessment of dementia..." with the Permission of the Canadian Medical Association. claims for specific diagnostic tests for Alzheimer's disease that will require careful study and further validation. ${ }^{10.18-20}$

\section{Non-Alzheimer dementias}

These are generally estimated to account for more than one third of all dementia cases, ${ }^{1.21 .22}$ but are less well characterised with respect to diagnosis, natural history and potential for therapeutic intervention. To further operationalize diagnostic criteria

Table 3. Suggested laboratory tests.

Consensus

(High, Med, Low)

\begin{tabular}{|c|c|c|c|c|c|c|}
\hline Test & $\mathbf{G}$ & $\mathbf{T}$ & $\mathbf{E}$ & ++ & + & $+1-$ \\
\hline Thyroid indices & $\mathrm{X}$ & & & ++ & & \\
\hline Metabolic disorders & & & & & & \\
\hline - electrolytes & $\mathrm{X}$ & & & ++ & & \\
\hline - calcium & $\mathrm{X}$ & & & ++ & & \\
\hline - glucose & $\mathrm{X}$ & & & ++ & & \\
\hline$-\mathrm{BUN} / \mathrm{Cr}$ & & $x$ & & & + & \\
\hline - Ser amm & & $\mathrm{X}$ & & & & \\
\hline $\mathrm{CBC}$ & $\mathrm{X}$ & & & ++ & & \\
\hline CT scan (cranial) & & $X$ & & ++ & & \\
\hline Drug levels & & $\mathrm{X}$ & & ++ & & \\
\hline $\begin{array}{l}B_{12} \text { (in the face of } \\
\text { a normal CBC) }\end{array}$ & & $\mathrm{X}$ & & & + & \\
\hline Folic acid & & $\mathrm{X}$ & & & + & \\
\hline $\begin{array}{l}\text { Water soluble } \\
\text { vitamin levels }\end{array}$ & & $X$ & & ++ & & \\
\hline HIV & & $x$ & & ++ & & \\
\hline Syphilis serology & & $\mathrm{X}$ & & ++ & & \\
\hline Heavy metals & & $\mathrm{X}$ & & ++ & & \\
\hline Chest $\mathrm{X}$ ray & & $\mathrm{X}$ & & ++ & & \\
\hline Mammogram & & $\mathrm{X}$ & & & + & \\
\hline Serum cortisol & & $\mathrm{X}$ & & ++ & & \\
\hline Serum lipids & & & $\mathrm{X}$ & ++ & & \\
\hline EEG & & & $\mathrm{X}$ & & ++ & \\
\hline Urinalysis & & & $\mathrm{X}$ & & ++ & \\
\hline $\mathrm{ECG}$ & & & $x$ & & & + \\
\hline Arterial blood gas & & & $X$ & & & + \\
\hline Lumbar puncture & & & $\mathrm{X}$ & & ++ & \\
\hline $\mathrm{PT} / \mathrm{PTT}$ & & & $X$ & & & + \\
\hline Carotid doppler studies & & & $X$ & & ++ & \\
\hline ESR & & & $\mathrm{X}$ & & ++ & \\
\hline
\end{tabular}

\section{Notes:}

$\mathrm{G}$

T Targeted (for selected patients, depending on the history and physical exam)

E Exclude (test not indicated for most patients)

$\mathrm{BUN} / \mathrm{Cr} \quad$ Blood urea nitrogen/serum creatinine

Ser amm Serum ammonia

CBC Complete blood count

PT/PTT Prothrombin/partial thromboplastin time

ESR Erythrocyte sedimentation rate

Reprinted from "Organizing Committee, Canadian consensus conference on the assessment of dementia..." with the Permission of the Canadian Medical Association. 
and assess natural history of these important disorders, a uniform Canadian data base is currently planned by the C5R.

For vascular dementias, traditional classification schema have included the Hachinski Ischemic Score and its modified versions. ${ }^{23.24}$ Further updated diagnostic proposals have recently been put forward worldwide and are being tested. ${ }^{25-27}$

Other adult onset degenerative disorders such as Lewy body disease, ${ }^{28,29}$ Parkinsonian dementia ${ }^{30,31}$ and the spectrum of frontal dementias ${ }^{32-36}$ serve as examples of the disorders that must have operationalized criteria, to permit any meaningful clinical trials.

Research diagnostic criteria must be defined for all major causes of degenerative dementia, as a prelude to reliable epidemiological and therapeutic studies.

\section{TheraPEUTIC DESIgN}

The prevalence and availability of validated diagnostic criteria for Alzheimer's disease make it currently the main target of experimental therapeutic intercession in the context of dementia. Much of the discussion that follows is therefore centred on this disease, but many of the general concepts outlined will also apply to the non-Alzheimer-type dementias.

\section{Disease Stages}

Comprehensive studies of the natural history of Alzheimer's disease allow for effective staging of the illness (e.g. ${ }^{37-40}$ ). Instruments such as the Clinical Dementia Rating Scale (CDR), ${ }^{38.39}$ the Global Deterioration Scale (GDS) ${ }^{40}$ and the Functional Rating Scale (FRS) ${ }^{41}$ ) have been validated and include multidimensional assessment of behaviour, cognition and function. These instruments are appropriately finding increased use in clinical trials. Experimental treatment strategies to date have not addressed the full spectrum of disease stages, generally restricting inclusion to CDR scores $0.5-2$, and GDS 4-5. Virtually all clinical trials have narrowly centred on these mild to moderate disease stages, with a major focus on cognitive efficacy. This approach will need correction. In either the prodrome of the disease or in the presymptomatic stages (CDR 0-0.5 and GDS 1-3), the emerging biological markers will in all likelihood allow for the development of early therapeutic intercession, where the goal will be the delay of symptomatic manifestations. In the latter stages of this disease (CDR 3 or more, GDS 6 or more) behavioral problems are paramount. These have been largely ignored in the context of experimental therapy in general and drug development in particular. This must be addressed as caregiver stress and institutionalization generally result from unmanageable behaviour rather than cognitive impairment.

Therapeutic goals should be defined more broadly to include all disease stages and thereby provide treatment possibilities across the entire spectrum of this illness. The development and validation of multidimensional disease assessment scales for Alzheimer's disease allows for more comprehensive disease staging and their emphasis in assessing new therapies is advocated.

\section{Study Design}

The heterogeneity of Alzheimer's disease with respect to clinical features and natural history poses a considerable challenge to the conduct of clinical trials. In particular, the observation of subgroups in this illness (e.g. ${ }^{42-44}$ ) including early versus late onset disease, ${ }^{45.46}$ slow versus fast progression, ${ }^{43.47}$ early aphasia ${ }^{48}$ and extrapyramidal features ${ }^{42,49-51}$ complicates the issue of subject selection and the interpretation of results. Studies to date have included a highly restricted patient population with "probable" Alzheimer's disease, generally without comorbidity. In our experience, currently, as many as 10-20 "probable" Alzheimer disease patients may be screened to enrol a single patient in a trial. At the conclusion of studies using such samples, there is uncertainty as to who will benefit from the therapy in the Alzheimer patient population at large. Further, the precise definition of acceptable efficacy to toxicity ratios in these generally elderly, often fragile patients will only be answerable with more representative patient populations being studied.

Another design concern is the need for placebo controls. Although such designs are recognised to be particularly helpful in the context of cognitive and behavioral disorders, the requirement of long term exposure to placebo to evaluate strategies such as disease stabilization raises serious ethical concerns. The use of historical control data accumulating from longitudinal Alzheimer research studies ${ }^{52.53}$ might offer a possible alternative to placebo controlled trials.

Representative diversity of both patients and research sites is desirable to allow for a balanced sample reflecting regional, ethnic and socio-economic status diversity. The above issues may be addressed through the use of multicentre trials, particularly if they cross national boundaries and continents. Multicentre trials also allow for the necessary larger sample sizes to deal with the heterogeneity of this illness and the relatively modest treatment effects.

The distribution of dementia diagnoses in other countries may be considerably different from Canadian figures (e.g. ${ }^{54,55}$ ) and results of clinical trials with the same agent may yield results specific to an individual country (e.g., ${ }^{56,57}$ ).

Large sample size multicentre trials are most effective in addressing the heterogeneity of Alzheimer's disease and provide the best avenue for harmonization of trial populations, outcome measures and assessment of therapeutic efficacy.

\section{Phases of Drug Development \\ Phase I}

Traditionally, Phase I studies have been conducted with healthy volunteers, young and old, for the purpose of elucidating kinetics, pharmacodynamics, toxicity and tolerance to pharmacologic agents.

As new therapeutic avenues outside of the traditional pharmacologic realm (including tissue transplantation, the use of growth factors and genetic engineering) rapidly evolve, alternative approaches to Phase I will need to be considered.

\section{Phase II}

The traditional role of phase II studies has been the evaluation of the safety and efficacy of drugs in small, well defined, restricted patient groups. However the need to accelerate drug development, and concerns related to cost and similar issues are often leading to a broader approach of combining phases II and III. Caution is needed with the uncritical adoption of this strategy. 
Studies become highly restricted and results cannot be applied across the spectrum of Alzheimer's disease.

The traditional clear separation of Phase II and III would therefore continue to be desirable.

\section{Phase III}

This phase allows for data acquisition to support the safety and efficacy necessary for drug labelling. Individuals across the entire spectrum of the disease should be studied, with comorbid medical problems and with their concomitant medication requirements. The stated goal would be to test the treatment in question on a sample of the population for whom it is ultimately intended. This refocus of phase III development would also address some of the ethical concern of subject exclusion for reasons other than safety.

Phase III studies in Alzheimer's disease should include a broad sample of patients with comorbid medical problems and with concomitant medications commonly required in the elderly.

\section{Phase IV}

The traditional post-marketing phase of pharmaceutical development has been to provide safety surveillance. In Alzheimer's disease, this phase, if emphasized by regulatory authorities, could allow for an opportunity to assess long term clinical pharmacoeconomic benefits, as well as the duration of treatment effects. Clinical trials have not generally allowed for these assessments to be made in the earlier phases of development. Recognizing the chronicity of the disease, its long course, and the potential costs that will be incurred by indefinite treatment duration, this phase will likely take on new importance as public pressure for drug release mounts.

Phase IV studies in Alzheimer's disease should complement pre-marketing studies by the collection of long-term clinical and pharmaco-economic data.

\section{Measurement}

The phenomenology of dementia demands that reliable measurement indices be established for cognitive, behavioral, functional and biologic parameters. These measurements should be ecologically valid and clinically meaningful. At present, measurements are often inadequately defined and there is variable agreement with respect to their relative merit.

\section{Cognitive Domains}

Currently the Alzheimer's Disease Assessment Scale (ADAS) $^{58,59}$ is the most widely used outcome measure in clinical trials in North America. It combines both cognitive and noncognitive assessment. Its use has been dictated principally by the relative familiarity of both investigators and regulatory bodies with this instrument, however, its ability to capture the important domains of Alzheimer's disease and its ecologic validity remain uncertain.

One important criterion in selecting a scale for use as a cognitive outcome measure in clinical trials is its ability to distinguish affected individuals (in the early phases of illness) from normal controls. This is necessary, in order to measure potential improvement in response to a given treatment. While ultimately a pool of neuropsychological tests might best fulfil this requirement, careful examination of this issue for any proposed battery appears important. Comparison of scales against the ADAS, such as recently undertaken, ${ }^{60}$ with the ADAS-Cognitive and the Repeatable Battery for the Assessment of Dementia (RBAD) $)^{61.62}$ and the Cognitive Drug Research Computerized Battery $(\mathrm{CDR})^{63}$ might become a requirement prior to the adoption of new scales in clinical trials. In that particular comparison, the ADAS-Cognitive scale distinguished Alzheimer's patients from normals on 3 of 7 subscales, and on total score, correctly classifying $67 \%$ of $\mathrm{AD}$ patients and $86 \%$ of normal controls. The RBAD appeared to reliably differentiate Alzheimer's from normals, correctly classifying $80 \%$ and $79 \%$ respectively, with 3 of 6 subtests and total score distinguishing the two groups. The CDR system correctly classified $77 \%$ of AD patients and $87 \%$ of normal controls, based on significant differences on nine of twelve subtest measures and two summary scores. ${ }^{62}$ This would suggest that scales other than the ADAS-cognitive might offer alternatives and that the search for better approaches should remain active.

Current instruments in use in clinical trials, including ADAScognitive, also do not adequately address several important cognitive domains known to be affected in Alzheimer's disease. These include specific memory systems, executive functions, agnosias and attention.

In the realm of cognitive function, the choice of outcome measures is further complicated by potential floor and ceiling effects in this population. While most currently employed instruments are useful with mild to moderate dementia, more severely impaired subjects cannot be adequately assessed with these measures.

Several new assessment techniques for the more advanced patient have been proposed (e.g. ${ }^{64-66}$ ). The "Test for Severe Impairment" (TSI) requires only a brief evaluation time and assesses well-learned motor performance, language comprehension, language production, immediate and delayed memory, general knowledge and conceptualization. A test with the same target population, the Severe Impairment Battery (SIB), 66.67 requires slightly more administration time than the TSI, is composed of simple, one-step commands presented in conjunction with gestural cues and allows for scoring of non-verbal and partially correct responses. A conceptually novel approach applies Piagetian measures of cognition to this population. ${ }^{65}$ This may provide a valuable alternative in the assessment of severely impaired individuals. .5

With the advent of longer duration treatment studies, combinations of cognitive test measures are likely to be needed and their combined use will require validation.

Cognitive measurement instruments should have the ability to detect improvement in the mild as well as the severe stages of the disease. Further, they should be ecologically valid and sample cognitive domains relevant to the clinical expression of the illness. Current standards will need to be revised accordingly.

\section{Behavioral Domains}

The need to assess behaviour as a central part of the Alzheimer syndrome has been increasingly recognized (e.g. ${ }^{58.68-70}$ ). More than half of patients with Alzheimer's disease are estimated to develop depression..$^{71-74}$ The most commonly used depression scales such as the Hamilton Depression Scale, ${ }^{75}$ the Beck Depression Inventory ${ }^{76}$ and the Cornell Depression Scale ${ }^{77}$ require a certain degree of cognitive intactness and insight. In 
the dementia context, the transition points in their utility are not clearly established and may require additional caregiver input, a requirement stipulated by the Cornell Depression Scale. ${ }^{77}$

Psychotic symptoms occur in over 50\% of patients, most often in moderately to severely impaired individuals. ${ }^{78}$ In this regard, the selection of behavioral measurement instruments should include the domains of disturbed thought, sleep wake cycle as well as pacing and wandering. The Behave- $\mathrm{AD}^{69}$ is well validated and normed and captures the important domains of concern in this context.

Dementia specific depression scales which allow for caregiver input are required. Reliable transition points of patient self report will need to be clarified. Inventories for disturbed behaviour need to be specific for Alzheimer's disease and dementia use. The Behave-AD fulfils this requirement and its use is recommended in the assessment of major behavioral pathology in Alzheimer's disease.

\section{Functional Assessment (Activities of Daily Living)}

Functional disabilities in activities of daily living (ADL) are often the first clinical indicators of dementia and are recognized as an important part of the disease process. The observed loss of functional autonomy in Alzheimer's disease progresses from instrumental ADL to basic ADL: financing, homemaking, travelling, dressing, personal hygiene, toileting, eating and continence. The process is closely linked to the deterioration of executive functions, such as initiation, planning and organization of action, and effective completion of the activity. The loss of functional autonomy does not parallel the loss of cognitive functions.$^{79}$ Coupled with intermediate-stage behavioral changes in Alzheimer's disease, the caregiver burden from loss of functional autonomy may be a determinant factor for early institutionalization. ADL scales used in most clinical trials have been borrowed from scales used in non-demented populations, usually with physical disabilities quite unlike patients in early or intermediate-stages of Alzheimer's disease. ${ }^{80,81}$ The Disability Assessment in Dementia (DAD), a newly developed French/English scale, has been generated for proxy-respondents, caring for patients with Alzheimer's disease living at home, based on the hierarchy of losses in ADL and on its process. ${ }^{82}$

It is recommended that scales developed specifically for patients with Alzheimer's disease, such as the DAD, be used in each therapeutic trial.

\section{Global Clinical Impressions}

The clinical effectiveness of new treatments should be apparent to experienced clinicians assessing patients. ${ }^{83} \mathrm{~A}$ clinical global assessment can allow for these observations to be made, however the lack of structure and guidelines for the administration of current scales used for this purpose, limits their utility. Multidimensional scales such as the CDR and the FRS employing the sum of the boxes rather than a forced stage could serve this purpose. In the United States, the Clinical Interview Based Impression of Change (CIBIC), (unpublished letter to investigator from Paul Leber, 1991) has been advocated for use, but this is not without controversy. While attempting to give more structure to the concept of Clinical Global Impression (CGI), this technique has yet to be rigorously validated.

The importance of clinical global impressions is recognised in establishing that a treatment strategy is clinically relevant.
Current scales however lack structure, clear administration guidelines and validation. The option of using multidimensional scales where scores can be summed is recommended.

\section{Imaging of Biological Activity}

Use of neuroimaging parameters as outcome measures in the development of new therapies is continually advancing. While the technologies for physiologic measurement are available, their routine use has been restricted by technical complexity, cost and lack of sufficient experience to establish correlations to functional outcome. Recent technological advances and increasingly standardized scientific data collection and interpretation will allow for their use in the mainstream of antidementia drug development. The following major approaches are currently most often used, either singly or in combination:

\section{Positron Emission Tomography (PET)}

Radionuclide emission tomographic studies in Alzheimer's disease have demonstrated that there are characteristic regional patterns of impaired cerebral blood flow (CBF) and metabolism ${ }^{84-88}$ and a linear relationship between them has been established ${ }^{89}$ Metabolic changes have additionally been correlated to regional histopathologic abnormalities. ${ }^{90.91}$ Identification of disease subgroups (e.g. ${ }^{47}$ ) may be facilitated by this technology but verification is still needed and results have been mixed. ${ }^{84,92,93}$

This technology could also be of potential value in establishing the diagnosis and in assessing efficacy of treatments in individuals with higher premorbid function or early disease. ${ }^{94}$ Studies of cerebral pharmacodynamics have shown the effects of neuroactive drugs on regional glucose metabolism as an index of regional synaptic activity. ${ }^{95-98}$ Effects of successful pharmacologic treatment on metabolic pattern associated with other neurological diagnoses have been carried out as well. ${ }^{99,100}$

Activation paradigms ${ }^{101-103}$ might provide a more powerful means of quantifying specific effects of drugs on cognitive function. These paradigms include utilizing $\mathrm{H}_{2}{ }^{15} \mathrm{O}$ PET to image brain function during the execution of memory tasks and then assessing the effects of neuroactive drug treatments on these same endpoints. ${ }^{104-106}$

New PET methodologies also allow for specific labelling of neurotransmitters and/or their receptors ${ }^{107}$ with the potential that responders to specific compounds might be identified. This might thus also provide a promising avenue for the evaluation of novel therapies. ${ }^{108}$ The cost, availability of radioactive materials, and relative invasiveness of this technology however will continue to limit a more widespread application to clinical trials.

\section{Single Photon Emission Tomography (SPECT)}

Single photon emission computed tomography, a nuclear imaging technique that also measures cerebral blood flow and receptor distribution, reveals the characteristic abnormalities of Alzheimer's disease established with PET. ${ }^{109}$ The sensitivity and specificity of these SPECT patterns in Alzheimer's disease have yet to be well established however.

Unlike PET methodology, which allows for quantitative measurement of metabolic parameters, the analysis of SPECT is restricted at present to semiquantitative measurement of regions of interest. While SPECT studies can potentially be quantified, most of the work in the quantification of external imaging techniques has been carried out in PET. Promising development 
of receptor binding radionuclides with QNB binding have potential application to neurotransmitter systems affected in Alzheimer's disease. ${ }^{110}$ Such receptor labelling may again allow for better understanding of drug action in Alzheimer's disease and the identification of responders to compounds modifying specific neurotransmitters.

The widespread availability, better tolerance by patients and considerably lower cost of SPECT compared to PET, offers the promise for a key role in the development of new treatment strategies. Realization of this potential will depend upon the development of appropriate quantification techniques.

\section{Magnetic Resonance Imaging (MRI)}

Both PET and SPECT technologies are limited by their relative invasiveness in terms of radioactive exposure and their use in repeat monitoring is therefore limited. While structural MRI has not been useful as an outcome measure in drug development, the evolution of expanded MRI modalities, including functional and spectroscopic imaging, may offer greater potential in this context. On H1 MR Spectroscopy there are reported characteristic abnormal metabolic profiles of Alzheimer's patients ${ }^{17}$ which are to be tested in longitudinal research for their potential utility. Functional MRI also holds considerable promise as a tool in drug development, since it allows potentially for the assessment of the same endpoints as $\mathrm{H}_{2}{ }^{15} \mathrm{O}$ PET, without the attendant cost or radiation exposure. This technique could accordingly permit comprehensive dose response studies, the comparison of acute versus chronic drug effects over time, as well as evaluation of the effects of therapy over the natural history of an illness. Specific therapeutic intervention might then also be assessed non-invasively in terms of drug effects on synaptic activity in specific regions of the brain. Like PET, the combination of activation and drug treatment paradigms could potentially be used. ${ }^{104-105.111}$ The realization of the potential of this technology in the context of clinical trials will depend on its technical maturation.

\section{Quantitative Electroencephalography (QEEG)}

On both regular and spectral EEG assessment, Alzheimer patients exhibit a higher percentage of slow wave delta and theta power, a lower percentage of fast wave activity and a general reduction in the mean frequency of the dominant brain rhythm. ${ }^{112-119}$

Quantitative (computer-assisted) topographic EEG (QEEG) measurements are reported to be sensitive indices in both mild and in early onset Alzheimer's disease, ${ }^{120,121}$ as well as in the different stages of disease progression. ${ }^{122,123}$ Recently, this technology has increasingly been employed in the early development of antidementia compounds (e.g., ${ }^{124}$ ). It appears to be sufficientily sensitive to allow for the determination of cerebral bioavailability of psychotropic substances and for their profiling in terms of dose-response and time response curves. ${ }^{125}$ QEEG may be useful as a neurophysiologic outcome measurement when a specific intervention demonstrates a shift towards a more normalised electrographic activity pattern. ${ }^{126-128}$ The non-invasiveness of QEEG, together with its ability to be applied painlessly and without subject risk due to attendant radioactivity make this an attractive option for use in clinical trials. Further, the relatively lower associated costs compared to other technologies, make this a particularly useful tool for investigating brain functions continuously and repeatedly during early Phase I drug development as well as in larger Phase II clinical studies.

\section{Combined Multimodal Imaging}

Although major advances have been made in many neuroimaging modalities during the past 20 years, each has relative limitations in terms of spatial/temporal resolution, the specific nature of the processes measured, and cost and feasibility factors. For a more accurate diagnosis and a complete assessment of CNS impact of treatments a more thorough knowledge of activity throughout the neuraxis is needed, requiring information from several imaging modalities. With the the relatively good image resolution of MRI comes the opportunity to superimpose functional images from EEG, PET and evoked potentials onto 3dimensional anatomical maps. ${ }^{129} \mathrm{~A}$ number of laboratories throughout the world have successfully superimposed various imaging modalities (e.g., MRI and EEG) with a consequent advancement of anatomical and functional resolution which may lead to a deeper understanding of the cognitive/neural network abnormalities and their changes throughout the course of dementia. ${ }^{130}$

\section{THERAPEUTIC APPROACHES}

While there is currently no approved benchmark treatment available in Canada for Alzheimer's disease, an ever expanding number of clinical trials are being conducted in this country. The pharmacologic approaches used over the last decade have been broad and their results have been variable. Studies have often reported positive results on small numbers of patients and the reproduction of positive studies has been limited. There have frequently been serious methodological problems in these studies. As the pathophysiology of Alzheimer's disease is better understood, pharmacologic strategies will find a more rational footing and prior approaches will likely become obsolete. At this juncture, in addition to the traditional pharmacologic avenues, advances in molecular genetics, and biotechnology offer hope for alternative therapeutic development.

\section{Pharmacologic}

These can be broadly classified into symptomatic, and stabilization approaches.

\section{Symptomatic Therapies}

In proposing a medication as a putative symptomatic treatment for Alzheimer's disease, it is essential that several issues be addressed. The first is the identification of which symptomatic domains of cognition, behaviour, or function the treatment is intended to improve. Second, it is mandatory that symptomatic treatment effects be clinically apparent and meaningful. Third, an assessment of the timeline of efficacy of a new treatment should be undertaken in its phased development. This should include establishing endpoints of symptomatic treatments and the operational criteria that might be used for such a determination. Fourth, pharmacoeconomic impact should be measured during drug development prior to presentation to regulatory authorities. An effective symptomatic treatment should include either reduction of care costs, and/or an improved quality of life for patient and/or caregiver.

\section{Stabilization Therapies}

In proposing a medication as a putative stabilization treatment for Alzheimer's disease, several issues need to be addressed. First there is a need to demonstrate that the agent in 
question significantly slows disease progression. Currently, global staging instruments such as the CDR, FRS and GDS are the most accessible instruments to demonstrate disease slowing. In using these instruments effectively, there should be a minimum interval of 6 months between assessments and a total evaluation period of $>12$ months, as the measurement of global change is less reliable for shorter periods. ${ }^{52}$

Secondly, the pharmacoeconomic impact of such a treatment should again be measured in its phased development prior to its presentation to regulatory authorities. A comparative reduction of care costs and service utilization should be demonstrated.

It is recommended that an indication for symptomatic treatment of Alzheimer's disease is supported by a demonstration of efficacy within at least one of the individual domains affected (cognition, behaviour, function). There would however be no obligation to show a significant effect on global staging scores. On the other hand, for an indication of disease stabilization, a global staging of efficacy would be mandatory without the obligation to demonstrate specific efficacy in an individual domain.

A distinction between long-term symptomatic effects and stabilization remains to be clarified.

\section{Molecular Biology and Biotechnology}

Emerging biotechnology is rapidly widening the scope of potential treatment strategies. The successful in vitro production of recombinant nerve growth factors and improved methods for their transportation across the blood-brain barrier ${ }^{131}$ may allow for clinical trials in Alzheimer's disease in the near future. Nerve growth factors are being applied to other neurodegenerative disorders ${ }^{132}$ and could have applications in Alzheimer's disease. Fetal tissue transplantation is another strategy currently being considered. These new approaches may be symptomatic and/or stabilizing and will need to be evaluated accordingly.

As knowledge of the molecular genetics of Alzheimer's disease continues to evolve, genetic interventions on identified mutations and other aspects of the convergence cascade ${ }^{133}$ of Alzheimer's disease may become possible. The mutations on chromosomes 14 and 21 in early onset familial Alzheimer's disease ${ }^{134-137}$ as well as the Apolipoprotein $E$ allelic markers on chromosome $19^{10-13}$ in late onset familial and sporadic Alzheimer's disease have allowed an expanded characterisation of the pathophysiologic events. The $\mathrm{B}-\mathrm{A} 4$ amyloid protein fragment may have a central pathogenetic role in Alzheimer's disease $^{14}$ and might be a biologic marker. Evolving therapeutic strategies may allow for the reduction of $B$-amyloid production through protease inhibitors. APO-E interventions are yet to be developed.

The precise potential for therapeutic intervention on this basis remains to be determined, but if realized, current guidelines will need amendment to include presymptomatic therapies.

\section{RISK/BENEFIT FACTORS}

As an incurable disease, there is ever increasing pressure to develop therapies rapidly and to allow their general use as early as possible. As the discussions of the risks and benefits to patients in this process are intensifying, a number of dilemmas are apparent. The progressive nature of this illness requires intercession as quickly as possible, while non-judicious use of inadequately tested treatments with doubtful efficacy and significant toxicity can be injurious and is clearly undesirable.

The age effect of this disease dictates that elderly patients, often frail and with comorbid disease, will be the individuals for whom new treatments are developed. In terms of pharmacologic therapies, the question of the acceptable ratio of efficacy against toxicity is being debated. There are currently no accepted indices for this measurement and their development is urgently required as the number of new drug applications to the Health Protection Branch is increasing. The effective and difficult to measure "quality of life" is also an important variable in the evaluation of the efficacy/toxicity ratio of a given compound that needs attention.

A further concern with respect to emerging biotechnological therapies for Alzheimer's disease is the absence of reliable animal models for investigation. The "new biology" of nerve growth factors, genetically engineered tissues, and other tissue modifying techniques pose both ill-defined risks as well as considerable opportunity. While showing therapeutic promise they may also have significant risks with respect to oncogenesis, aberrant synaptogenesis, paradoxical increases in $\beta$-amyloid and tau protein production. Further, these interventions could create aberrant positive feedback loops. The question of whether human experimentation will therefore be justifiable or necessary will require complex ethical considerations. This is mitigated by the fact that other neurodegenerative illnesses, mainly Parkinson's disease, for which there are more satisfactory animal models, have been safely approached with some of these techniques. If the proposal that neurodegenerative illnesses share pathogenetic mechanisms, at least in their early stages, is indeed correct, the rationale for the use of tissue modifying techniques in indications without satisfactory animal models may be stronger.

The risk/benefit ratio also has to be evaluated from a pharmacoeconomic perspective. In the face of the ever shrinking economic base of the Canadian health care system, there is a need to consider in addition to relative clinical efficacy the direct and indirect cost of care. Provincial formularies in Canada will be facing difficult decisions as to which particular therapeutic agents to cover, with important cost implications to an aging population with limited means. The cost of monitoring for potential toxicity may well pose an additional barrier to universal access. There is clearly a need in the development of antidementia therapies to focus not only on statistically significant results of primary efficacy, but on the full range of clinical effects, valid risk/benefit assessment, quality of life and pharmacoeconomics.

In summary, there is now recognition of the magnitude of the problem of dementia and its impact on Canadian society. This is reflected in the collaborative efforts of the research community, industry and government. The further development of standardized diagnostic criteria, the creation of uniform data bases and the advent of reliable biological markers for dementing disorders allow for more meaningful clinical research and therapeutic trials. The striking advances in this field made possible by the "new biology" make it increasingly likely that effective therapeutic intercessions, with marked improvement in quality of life, a low risk/benefit ratio and meaningful pharmacoeconomic benefit will indeed be discovered. 


\section{ACKNOWLEDGEMENTS}

The authors gratefully acknowledge the thoughtful feedback on this manuscript by Dr. Catherine Peterson, Health Protection Branch, Dr. Allen Braun, National Institutes of Health and Dr. Verner Knott, Institute of Mental Health Research. The Consortium of Canadian Centres for Clinical Cognitive Research (C5R) provided conceptual and financial support for this project.

\section{REFERENCES}

1. Canadian study on health and aging: study methods and prevalence of dementia. Can Med Assoc J 1994; (in press).

2. Max W. The economic impact of Alzheimer's disease. Neurology 1993; 43 (Suppl. 4): S6-S10.

3. The ICD-10 Classification of Mental and Behavioural Disorders: Clinical Descriptions and Diagnostic Guidelines, World Health Organization, 1992.

4. Cummings JL, Benson DF. Dementia: A Clinical Approach, 2nd edition. Boston: Butterworth-Heinemann 1992: 1-2

5. American Psychiatric Association, Diagnostic and statistical manual of mental disorders: Revised, 3rd edition. Washington, D.C.: American Psychiatric Association, 1987.

6. Organizing Committee Canadian concensus conference on the Assessment of Dementia. Assessing dementia: the Canadian consensus. Can Med Assoc J 1991; 144: 851-853.

7. McKhann G, Drachman D, Folstein M, Katzman R, Price D, et al. Clinical diagnosis of Alzheimer's disease: report of the NINCDS-ADRDA working group under the auspices of Department of Health and Human Services Task Force on Alzheimer's Disease. Neurology 1984; 34: 939-944.

8. Tierney MC, Fisher RH, Lewis AJ, Zorzitto ML, Snow WG, et al. The NINCDS-ADRDA Work Group criteria for the clinical diagnosis of probable Alzheimer's disease: a clinicopathologic study of 57 cases. Neurology 1988; 38: 359-364.

9. Joachim CL, Morris JH, Selkoe DJ. Clinically diagnosed Alzheimer's disease: autopsy results in 150 cases. Ann Neurol 1988; 24: 50-56.

10. Poirier J, Davignon J, Bouthillier D, Kogan S, Bertrand P, et al. Apolipoprotein E polymorphism and Alzheimer's disease. Lancet 1993; 342: 697-699.

11. Corder EH, Saunders AM, Strittmatter WJ, Schmechel DE, Gaskell PC, et al. Gene dose of apolipoprotein E type 4 allele and the risk of Alzheimer's disease in late onset families. Science 1993; 261: 921-923.

12. Strittmatter WJ, Saunders AM, Schmechel D, Pericak-Vance M, Enghild J, et al. Apolipoprotein E: high-affinity binding to betaamyloid and increased frequency of type 4 allele in late-onset familial Alzheimer disease. Proc Natl Acad Sci U S A 1993; 90: 1977-1981

13. Saunders AM, Strittmatter WJ, Schmechel D, George-Hyslop PH, Pericak-Vance MA, et al. Association of apolipoprotein E allele epsilon 4 with late-onset familial and sporadic Alzheimer's disease. Neurology 1993; 43: 1467-1472.

14. Selkoe DJ. Amyloid protein and Alzheimer's disease. Sci Am 1991; Nov: 54-61.

15. Selkoe DJ. In the beginning. Nature 1991; 354: 432-433.

16. Cai X-D, Golde TE, Younkin SG. Release of excess amyloid B protein from a mutant amyloid B protein precursor. Science 1993; 259: 514-516.

17. Miller BL, Moats RA, Shonk T, Ernst T, Wooley S, et al. Alzheimer's disease: depiction of increased cerebral myo-inositol with proton MR spectroscopy. Radiology 1993; 187: 433437.

18. Ogomori K, Kitamoto T, Tateishi J, Sato Y, Suetsugu M, et al. Beta-protein amyloid is widely distributed in the central nervous system of patients with Alzheimer's disease. Am J Pathol 1989; 134: 243-251.

19. Petit D, Montplaisir J, Lorrain D, Gauthier S. Spectral analysis of the rapid eye movement sleep electroencephalogram in right and left temporal regions: a biological marker of Alzheimer's disease. Ann Neurol 1992; 32: 172-176.

20. Leuchter AF, Cook IA, Newton TF, Dunkin J, Walter DO, et al. Regional differences in brain electrical activity in dementia: use of spectral power and spectral ratio measures. Electroencephalogr Clin Neurophysiol 1993; 87: 385-393.
21. Katzman R. Alzheimer's disease. N Eng J Med 1986; 314: $964-$ 973.

22. Katzman R. Differential diagnosis of dementing illnesses. Neurol Clin 1986; 4: 329-340.

23. Hachinski VC, Lassen NA, Marshal J. Multi-infarct dementia: a cause of mental deterioration in the elderly. Lancet 1974; 2: 207210.

24. Rosen WG, Terry RD, Fuld PA, Katzman R, Peck A. Pathological verification of ischemic score in differentiation of dementia. Ann Neurol 1980; 7: 486-488.

25. Roman GC, Tatemichi TK, Erkinjuntti T, Cummings JL, Masdeu $\mathrm{JC}$, et al. Vascular dementia: diagnostic criteria for research studies. Report of the NINDS-AIREN International Workshop. Neurology 1993; 43: 250-260.

26. Chui HC, Victoroff JI, Margolin D, Jagust W, Shankle R, et al. Criteria for the diagnosis of ischemic vascular dementia proposed by the State of California Alzheimer's Disease Diagnostic and Treatment Centers. Neurology 1992; 42: 473-480.

27. Erkinjuntti T, Haltia M, Palo J, Sulkava R, Paetau A. Accuracy of the clinical diagnosis of vascular dementia: a prospective clinical and post-mortem neuropathological study. J Neurol Neurosurg Psychiatry 1988; 51: 1037-1044.

28. Burkhardt CR, Filley CM, Kleinschmidt-DeMasters BK, De la Monte S, Norenberg MD, et al. Diffuse Lewy body disease and progressive dementia. Neurology 1988; 38:1520-1528.

29. Edwards RJ, McKenzie JE, Roberts GW, Royston MC. Alzheimer's disease and Lewy body dementia. Br J Psychiatry 1993; 163: 692.

30. Litvan I, Mohr E, Williams J, Gomez C, Chase TN. Differential memory and executive functions in demented patients with Parkinson's and Alzheimer's disease. J Neurol Neurosurg Psychiatry 1991; 54: 25-29.

31. Mohr E, Mendis T, Grimes JD. Late cognitive changes in Parkinson's disease with an emphasis on dementia. In: Weiner WJ, Lang AE, eds. Behavioral Neurology of Movement Disorders. New York, Raven Press, 1994.

32. Gustafson L. Clinical picture of frontal lobe degeneration of nonAlzheimer type. Dementia 1993; 4: 143-148.

33. Clinton J, Mann DMA, Roberts GW. Frontal lobe dementia is not a variant of prion disease. Neurosci Lett 1993; 164: 1-4.

34. Purdon SE, Mohr E, Ilivitsky V, Jones BD. Huntington's disease: pathogenesis, diagnosis, and treatment. J Psychiatr Neurosci 1994; (in press).

35. Maj M. Organic mental disorders in HIV-I infection. AIDS 1990; 4: $831-840$.

36. Reinvang I, Froland SS, Skripeland V. Prevalence of neuropsychological deficit in HIV infection. Incipient signs of AIDS dementia complex in patients with AIDS. Acta Neurol Scand 1991; 83: 289-293.

37. Reisberg B, Ferris SH, De Leon MJ, Crook T. The Global Deterioration Scale for assessment of primary degenerative dementia. Am J Psychiatry 1982; 139: 1 136-1139.

38. Berg L. Clinical Dementia Rating (CDR). Psychopharmacol Bull 1988; 24: 637-639.

39. Hughes CP, Berg L, Danziger WL, Coben LA, Martin RL. A new clinical scale for the staging of dementia. Br J Psychiatry 1982; 140: $566-572$.

40. Reisberg B, Ferris SH, De Leon MJ, Crook T. Global Deterioration Scale (GDS). Psychopharmacol Bull 1988; 24: 661-663.

41. Crockett D, Tuokko H, Koch W. The assessment of everyday functioning using the present functioning questionaire and the Functional Rating Scale in elderly subjects. Clin Gerontol 1989; 8: 3-23.

42. Mayeux R, Stern Y, Spanton S. Heterogeneity in dementia of the Alzheimer type: evidence of subgroups. Neurology 1985; 35: 453-461.

43. Mann UM, Mohr E, Chase TN. Rapidly progressive Alzheimer's disease. Lancet 1989; 2: 799.

44. Mohr E, Mann UM, Chase TN. Subgroups in Alzheimer's disease: fact or fiction. Psychiatr J Univ Ott 1990; 15: 203-206.

45. Weinstein HC, Hijdra A, Van Royen EA, Derix MMA, Walstra G, et al. SPECT in early- and late-onset Alzheimer's disease. Ann N Y Acad Sci 1991; 640: 72-73. 
46. Haupt M, Kurz A, Pollmann S. Severity of symptoms and rate of progression in Alzheimer's disease: a comparison of cases with early and late onset. Dementia 1992; 3: 21-24.

47. Mann UM, Mohr E, Gearing M, Chase TN. Heterogeneity in Alzheimer's disease: progression rate segregated by distinct neuropsychological and cerebral metabolic profiles. J Neurol Neurosurg Psychiatry 1992; 55: 956-959.

48. Yesavage JA, Brooks JO,III, Taylor J, Tinklenberg J. Development of aphasia, apraxia, and agnosia and decline in Alzheimer's disease. Am J Psychiatry 1993; 150: 742-747.

49. Feldman H, Weir J, Bell K, Beattie BL. Extrapyramidal signs (EPS) in Alzheimer's disease: do they predict the rate of decline? Gerontologist 1993; 33: 176-177. (Abstract)

50. Mayeux R, Stern Y, Sano M. Heterogeneity and prognosis in dementia of the Alzheimer type. Bull Clin Neurosciences 1985; 50: 7-10.

51. Stern Y, Mayeux R, Sano M, Hauser WA, Bush T. Predictors of disease course in patients with probable Alzheimer's disease. Neurology 1987; 37: 1649-1653.

52. Morris JC, Edland S, Clark C, Galasko D, Koss E, et al. The Consortium to Establish a Registry for Alzheimer's Disease (CERAD). Part IV. Rates of cognitive change in the longitudinal assessment of probable Alzheimer's disease. Neurology 1993; 43: 2457-2465.

53. Morris JC, Heyman A, Mohs RC, Hughes JP, Van Belle G, et al. The Consortium to Establish a Registry for Alzheimer's Disease (CERAD). Part I. Clinical and neuropsychological assessment of Alzheimer's disease. Neurology 1989; 39: 1159-1165.

54. Skoog I, Nilsson L, Palmertz B, Andreasson LA, Svanborg A. A population-based study of dementia in 85 -year-olds. $\mathrm{N}$ Engl J Med 1993; 328: 153-158.

55. Osuntokun BO, Ogunniyi AO, Lekwauwa GU, Oyediran AB. Epidemiology of age-related dementias in the Third World and aetiological clues of Alzheimer's disease. Trop Geograph Med 1991; 43: 345-351.

56. Waters C. Cognitive enhancing agents: current status in the treatment of Alzheimer's disease. Can J Neurol Sci 1988; 15: 249256.

57. Claus JJ, Ludwig C, Mohr E, Giuffra M, Blin J, et al. Nootropic drugs in Alzheimer's disease: symptomatic treatment with pramiracetam. Neurology 1991; 41: 570-574.

58. Mohs RC, Rosen WG, Davis KL. The Alzheimer's Disease Assessment Scale: an instrument of assessing treatment efficacy. Psychopharmacol Bull 1983; 19: 448-450.

59. Rosen WG, Mohs RC, Davis KL. A new rating scale for Alzheimer's disease. Am J Psychiatry 1984; 141: 1356-1364.

60. Mohr E, Walker D, Randolph C, Sampson M, Wesnes K, et al. The utility of clinical trial batteries in the evaluation of dementia of different etiologies. Submitted 1994.

61. Randolph, C. Repeatable Battery for the Assessment of Dementia (RBAD). (In Press), New York: Psychological Corporation, 1994.

62. Walker, D. Distinguishing Huntington's dementia from Alzheimer's dementia in clinical trial batteries. Ottawa: M.A. Thesis, Carleton University, 1992.

63. Wesnes K. A fully automated psychometric test battery for human psychopharmacology. In: Abstracts of the IVth World Congress of Biological Psychiatry. Philadelphia, 1985: 153.

64. Albert M, Cohen C. The test for severe impairment: an instrument for the assessment of patients with severe cognitive dysfunction. Am Geriatr Soc 1992; 40: 449-453.

65. Sclan SG, Reisberg B. Functional assessment staging (FAST) in Alzheimer's disease: reliability, validity, and ordinality. Internat Psychogeriatr 1992; 4 (Suppl 1): 55-69.

66. Saxton J, Swihart AA. Neuropsychological assessment of the severely impaired elderly patient. Clin Geriatr Med 1989; 5: 531 543.

67. Panisset M, Roudier M, Saxton J, Boller F. A battery of neuropsychological tests for severe dementia. An evaluation study. [French]. Presse Medicale - Paris 1992; 21: 1271-1274.

68. Reisberg B, Borenstein J, Salob SP, Ferris SH, Franssen E, et al. Behavioral symptoms in Alzheimer's disease: phenomenology and treatment. J Clin Psychiatry 1987; 48 (Suppl 5): 9-15.
69. Reisberg B, Borenstein J, Franssen E. Behav-AD: A clinical rating scale for the assessment of pharmacologically remediable behavioral symptomatology in Alzheimer's disease. In: Altman HJ, ed. Alzheimer's disease: Problems, Prospects and Perspectives. New York, Plenum Press, 1987.

70. O'Leary PA, Haley WE, Paul PB. Behavioral assessment in Alzheimer's disease: use of a 24-hr log. Psychol Aging 1993; 8: $139-143$.

71. Kral VA. The relationship between senile dementia (Alzheimer type) and depression. Can J Psychiatry 1983; 28: 304-306.

72. Ron MA, Toone BK, Garralda ME, Lishman WA. Diagnosis accuracy in presenile dementia. Br J Psychiatry 1979; 134: 161168.

73. Liston EH. Diagnostic delay in presenile dementia. J Clin Psychiatry 1978; 39: 599-603.

74. Lazarus LW, Newton N, Cohler B, Lesser J, Schweon C. Frequency and presentation of depressive symptoms in patients with primary degenerative dementia. Am J Psychiatry 1987; 144: 41-45.

75. Hamilton M. A rating scale for depression. J Neurol Neurosurg Psychiatry 1960; 23: 56-62.

76. Beck AT, Ward CH, Mendelson M, Mock J, Erbaugh J. An inventory for measuring depression. Arch Gen Psychiatry 1961; 4: $56 \mathrm{i}-571$.

77. Alexopoulos GS, Abrams RC, Young RC, Shamoian CA. Cornell scale for depression in dementia. Biol Psychiatry 1988; 23: 271 284.

78. Drevets WC, Rubin EH. Psychotic symptoms and the longitudinal course of senile dementia of the Alzheimer type. Biol Psychiatry 1989; $25: 39-48$.

79. Gauthier L, Gauthier S. Assessment of functional changes in Alzheimer's disease. Neuroepidemiology 1990; 9: 183-188.

80. Linn MW, Linn BS. The rapid disability rating scale. Part 2. J Am Geriatr Soc 1982; 30: 378-382.

81. Lawton MP, Brody EM. Assessment of older people: self-maintaining and instrumental activities. Gerontologist 1969; 9: 179186.

82. Gauthier, L., Gauthier, S., Gelinas, I., McIntyre, M., WoodDauphinee, S. Assessment of functioning and ADL. Berlin: Sixth Congress of the IPA, 1993.

83. Rockwood K. Use of global assessment measures in dementia drug trials. J Clin Epidemiol 1994; 47: 101-103.

84. Cutler NR, Haxby JV, Duara R, Grady CL, Kay AD, et al. Clinical history, brain metabolism, and neuropsychological function in Alzheimer's disease. Ann Neurol 1985; 18: 298-309.

85. Friedland RP, Budinger TF, Ganz E, Yano Y, Mathis CA, et al. Regional cerebral metabolic alternations in dementia of the Alzheimer type: positron emission tomography with (18F) Fluorodeoxyglucose. J Comput Assist Tomogr 1983; 7: 590-598.

86. McGeer EG, Peppard RP, McGeer PL, Tuokko H, Crockett D, et al. ${ }^{18}$ Fluorodeoxyglucose positron emission tomography studies in presumed Alzheimer cases, including 13 serial scans. Can J Neurol Sci 1990; 17: 1-11.

87. Foster NL, Chase TN, Fedio P, Patronas NJ, Brooks RA, et al. Alzheimer's disease: focal cortical changes shown by positron emission tomography. Neurology 1983; 33: 961-965.

88. Heiss WD, Szelies B, Kessler J, Herholz K. Abnormalities of energy metabolism in Alzheimer's disease studies with PET. Ann N Y Acad Sci 1991; 640: 65-71.

89. Frackowiak RSJ, Pozzilli C, Legg NJ. Regional cerebral oxygen supply and utilization in dementia. A clinical and physiological study with oxygen-15 and positron tomography. Brain 1981; 104: $753-778$.

90. Brun A, Englund E. Regional pattern of degeneration in Alzheimer's disease: neuronal loss and histopathological grading. Histopathology $1981 ; 5: 549-564$.

91. Friedland RP, Brun A, Budinger TF. Pathological and positron emission tomographic correlations in Alzheimer's disease. Lancet 1985; 1(8422): 228.

92. Goto I, Taniwaki T, Hosokawa S, Otsuka M, Ichiya Y, et al. Positron emission tomographic (PET) studies in dementia. J Neurol Sci 1993; 114: 1-6. 
93. Haxby JV, Duara R, Grady CL, Cutler NR, Rapoport SI. Relations between neuropsychological and cerebral metabolic asymmetries in early Alzheimer's disease. J Cereb Blood Flow Metab 1985; 5: 193-200.

94. Heiss WD, Kessler J, Szelies B, Grond M, Fink G, et al. Positron emission tomography in the differential diagnosis of organic dementias. J Neural Transm 1991; Suppl 33: 13-19.

95. Leiderman DB, Balish M, Bromfield EB, Theodore WH. Effect of valproate on human cerebral glucose metabolism. Epilepsia 1991; 32: 417-422.

96. London ED. Studies of sigma receptors and metabolic responses to sigma ligand in the brain. NIDA Res Monogr 1993; 133: 55-68.

97. Theodore WH, Leiderman D, Gaillard W, Khan I, Reeves P, et al The effect of naloxone on cerebral blood flow and glucose metabolism in patients with complex partial seizures. Epilepsy Res 1993; 16: 51-54.

98. Grasby PM, Friston KJ, Bench C, Cowen PJ, Frith CD, et al Effect of the 5-HTIA partial agonist buspirone on regional cerebral blood flow in man. Psychopharmacology 1992; 108: 380 386.

99. Baxter LR, Jr. Neuroimaging studies of obsessive compulsive disorder. Psychiatr Clin North Am 1992; 15: 871-884

100. Baxter LR, Jr., Schwartz JM, Bergman KS, Szuba MP, Guze BH, et al. Caudate glucose metabolic rate changes with both drug and behavior therapy for obsessive-compulsive disorder. Arch Gen Psychiatry 1992; 49: 681-689.

101. Ohyama M, Senda M, Kitamura S, Terashi A. Changes in regional cerebral blood flow during auditory cognitive tasks - a PET activation study with odd-ball paradigm. Rinsho Shinkeigaku 1993; 33: 134-140.

102. Grady CL, Haxby JV, Horwitz B, Gillette J, Salerno JA, et al Activation of cerebral blood flow during a visuoperceptual task in patients with Alzheimer-type dementia. Neurobiol Aging 1993; 14: 35-44.

103. Heiss W-D, Pawlik G, Holthoff V, Kessler J, Szelies B. PET correlates of normal and impaired memory functions. Cerebrovasc Brain Metab Rev 1992; 4: 1-27.

104. Friston KJ, Grasby PM, Bench CJ, Frith CD, Cowen PJ, et al Measuring the neuromodulatory effects of drugs in man with positron emission tomography. Neurosci Lett 1992; 141: 106110

105. Friston KJ, Grasby PM, Frith CJ, Bench CJ, Dolan RJ, et al. The neurotransmitter basis of cognition: psychopharmacological activation studies using positron emission tomography. Ciba Found Symp 1991; 163: 76-87.

106. Heiss WD, Kessler J, Slansky I, Mielke R, Szelies B, et al. Activation PET as an instrument to determine therapeutic efficacy in Alzheimer's disease. Ann N Y Acad Sci 1993; 659: 327-331.

107. Shinotoh H, Asahina M, Inoue O, Suhara T, Hirayama K, et al. Effects of trihexyphenidyl and L-dopa on brain muscarinic cholinergic receptor binding measured by positron emission tomography. J Neural Transm [P-D Sect] 1993; 93: 102-110.

108. Karbe H, Wienhard K, Hamacher K, Huber M, Herholz K, et al. Positron emission tomography with $\left({ }^{18} \mathrm{~F}\right)$ methylspiperone demonstrates $D_{2}$ dopamine receptor binding differences of clozapine and haloperidol. J Neural Transm 1991; 86: 163-173

109. Jagust WJ, Budinger TF, Reed BR. The diagnosis of dementia with single photon emission computed tomography. Arch Neurol 1987; 44: 258-262.

110. Weinberger DR, Jones DW, Sunderland T, Lee KS, Sexton R, et al. In vivo imaging of cerbral muscarinic receptors with $\mathrm{l}-123$ QNB and SPECT: studies in normal subjects and patients with dementia. Clin Neuropharmacol 1992; 15 Suppl 1 Pt A: 194A-195A.

111. Binder JR, Rao SM, Hammeke TA, Yetkin YZ, Wong EC, et al. Functional magnetic resonance imaging (FMRI) of auditory semantic processing. Neurology 1993; 43 (Suppl 2): A189.

112. Coben L, Danziger W, Storandt M. Longitudinal EEG study of mild senile dementia of Alzheimer type: changes at 1 and 2-5 years. Electroencephalogr Clin Neurophysiol 1985; 61: 101-112.

113. Coben L, Chi D, Snyder A, Storandt M. Replication of a study of frequency analysis of the resting awake EEG in mild probable Alzheimer's disease. Electroencephalogr Clin Neurophysiol 1990; 75: 148-154.

114. Prinz P, Vitiello M. Dominant occipital (alpha) rhythm in early stage Alzheimer's disease and depression. Electroencephalogr Clin Neurophysiol 1989; 73: 427-432.
115. Breslav J, Starr A, Sicotte N, Higa J, Buchsbaum M. Topographic EEG changes with normal aging and SDAT. Electroencephalogr Clin Neurophysiol 1989; 72: 282-289.

116. Martin-Loeches M, Gil P, Jimenez F, Exposito F, Miguel F, et al. Topographic maps of brain electrical activity in primary degenerative dementia of the Alzheimer type and multi-infarct dementia. Biol Psychiatry 1991; 29: 211-223.

117. Duffy F, Albert M, McAnulty G. Brain electrical activity in patients with presenile and senile dementia of the Alzheimer type. Ann Neurol 1984; 16: 439-448.

118. Pennttila M, Partener V, Soininen H, Riekkinen P. Quantitative analysis of occipital EEG in different stages of Alzheimer's disease. Electroencephalogr Clin Neurophysiol 1991; 78: 89-96.

119. Soininen H, Partanen J, Laulumaa V, Helkala E, Laakso M, et al. Longitudinal EEG spectral analysis in early stage Alzheimer's disease. Electroencephalogr Clin Neurophysiol 1989; 72: 290297.

120. Coben LA, Danziger WL, Berg L. Frequency analysis of the resting awake EEG in mild senile dementia of the Alzheimer type. Electroencephalogr Clin Neurophysiol 1983; 55: 372-380.

121. Schreiter-Gasser U, Gasser T, Ziegler P. Quantitative EEG analysis in early onset Alzheimer's disease: a controlled study. Electroencephalogr Clin Neurophysiol 1993; 86: 15-22.

122. Ihl R, Maurer K, Dierks T, Frlich L, Perisic I. Staging in dementia of the Alzheimer type: topography of electrical brain activity reflects the severity of the disease. Psychiatry Res 1989; 29: 399 401

123. Soininen H, Partanen J, Pääkkönen A, Koivisto E, Riekkinen PJ Changes in absolute power values of EEG spectra in the followup of Alzheimer's disease. Acta Neurol Scand 1991; 83: 133 136.

124. Mohr E, Knott V, Mendis T. Cycloserine treatment in Alzheimer's disease. Neuropsychopharmacology 1993; 9: 96. (Abstract)

125. Herrmann WM, Irrgang U. An absolute must in clinico-pharmacological research: pharmaco-electroencephalography, its possibilities and limitations. Pharmacopsychiatry 1983; 16: 134-142.

126. Agnoli A, Martucci N, Manna V, Conti L, Fioravanti M. Effect of cholinergic and anticholinergic drugs on short-term memory in Alzheimer's dementia: a neuropsychological and computerized electroencephalographic study. Clin Neuropharmacol 1983;6: 311-323.

127. Sebban C. Quantified EEG: a possible tool for classification of SDAT and prediction of drug effects on cognition. Arch Gerontol Geriatr 1989; 1: 237-240.

128. Perryman KM, Fitten LJ. Quantitative EEG during a double-blind trial of THA and lecithin in patients with Alzheimer's disease. J Geriatr Psychiatry Neurol 1991; 4: 127-133.

129. Thatcher R, Toro C, Hatlett M. Multimodal registration of EEG, PET, MRI; analysis of neural network switching. $I n$ : Proceedings of the Society of Magnetic Resonance in Medicine; functional MRI of the brain, June 17-19. Arlington VA, 1993; 171-181.

130. Gevins A. High resolution EEG. Brain Topography 1993; 5: 321325.

131. Friden PM, Walus LR, Watson P, Doctrow SR, Kozarich JW, et al. Blood brain barrier penetration and in vivo activity of an NGF conjugate. Science 1993; 259: 373-377.

132. Brooks BR, Sanjak M, Mitsumoto H, Szirony K, Neville $H$, et al. Recombinant human ciliary neurotrophic factor ( $\mathrm{rHCNTF}$ ) in amyotrophic lateral sclerosis (ALS) patients: phase I-II safety, tolerability, and pharmacokinetic studies. Neurology 1993; 43: A416.

133. Blass JP. Pathophysiology of the Alzheimer's syndrome Neurology 1993; 43 (Suppl): S25-S38.

134. Goate A, Chartier-Harlin MC, Mullan M. Segregation of a missense mutation in the amyloid precursor protein gene with familial Alzheimer's disease. Nature 1991; 349: 704-706.

135. St. George-Hyslop P, Tanzi R, Polinsky RJ. The genetic defect causing Alzheimer's disease maps on chromosome 21. Science 1987; 235: 885-890.

136. Schellenburg GD, Bird TD, Wijsman EM. Genetic linkage evidence for a familial Alzheimer's disease locus on chromosome 14. Science 1992; 258: 668-671.

137. St. George-Hyslop P, Haines JL, Farrer LA. Genetic linkage studies suggest that Alzheimer's disease is not a single homogeneous disorder. Nature 1990; 347: 194-197. 